\title{
Early Modern Women
}

AN TNTERDISCIPLINARY JOURNAL

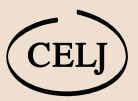

\section{Winner of the 2013 Council of Editors} of Learned Journals Voyager Award

for excellence in journals covering the period 1500-1800

Invites submissions of articles on the topic of women and gender in the early modern period. The Journal offers an award of $\$ 1000$ for the best article in each volume.

Early Modern Women: An Interdisciplinary Journal is the only journal devoted solely to the interdisciplinary and global study of women and gender spanning the late medieval through early modern periods. Each volume gathers essays on early modern women from every country and region, by scholars from a wide range of academic disciplines, including art history, cultural studies, music, history, languages and literatures, political science, religion, theatre, history of science, and history of philosophy.

\section{EDITORS}

Bernadette Andrea, Professor of English University of California, Santa Barbara bernadette.andrea@english.ucsb.edu

Julie D. Campbell, Professor of English Eastern Illinois University jdcampbell@eiu.edu

\section{Allyson M. Poska, Professor of History}

University of Mary Washington

aposka@umw.edu

SUBMISSIONS acmrs.org/emwsubmissions Editorial inquiries: emwj@umw.edu

\section{SUBSCRIBE acmrs.org/subscribe}

Subscription inquiries: emwjournal@asu.edu

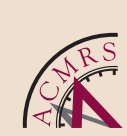

Early Modern Women: An Interdisciplinary Journal is published by the

Arizona Center for Medieval and Renaissance Studies Tempe, Arizona

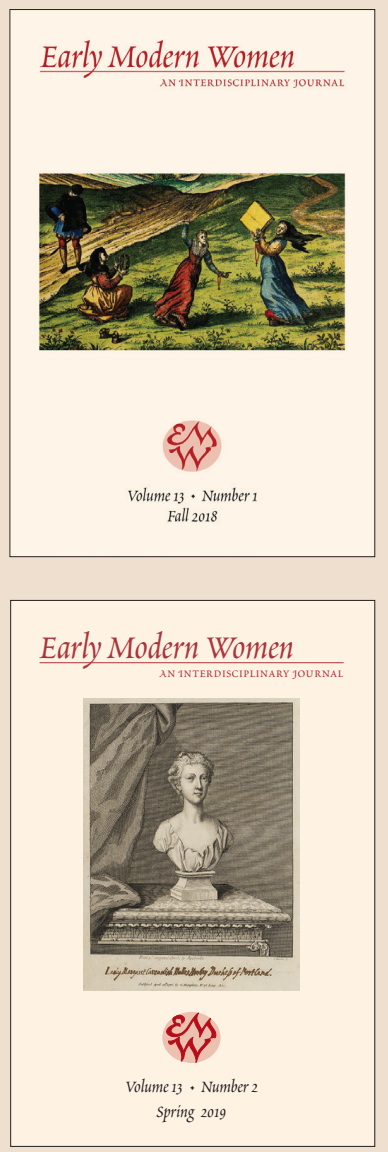


The Other Voice in Early Modern Europe:

The Toronto Series
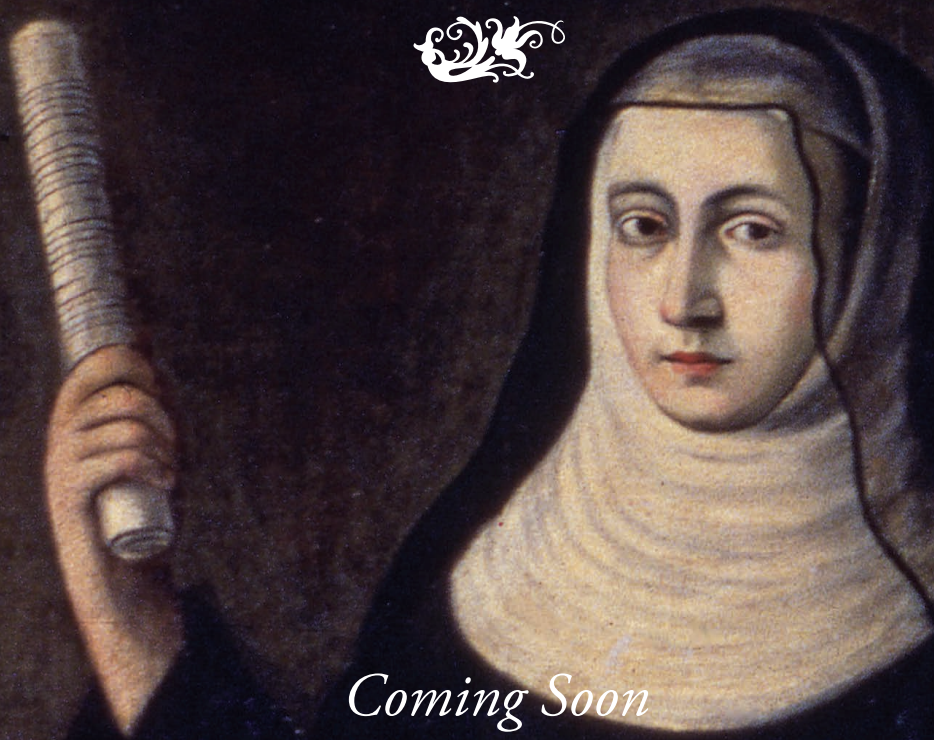

Arcangela Tarabotti

Antisatire: In Defense of Women, against Francesco Buoninsegni Edited and translated by Elissa B. Weaver

\section{Arcangela Tarabotti \\ Convent Paradise}

Edited and translated by Meredith K. Ray and Lynn Lara Westwater

PUBLISHED BY ITER PRESS AND ARIZONA CENTER FOR MEDIEVAL AND RENAISSANCE STUDIES

TO PURCHASE: acmrs.org/catalog

ENQUIRIES: iter@utoronto.ca | 416 -978-7074

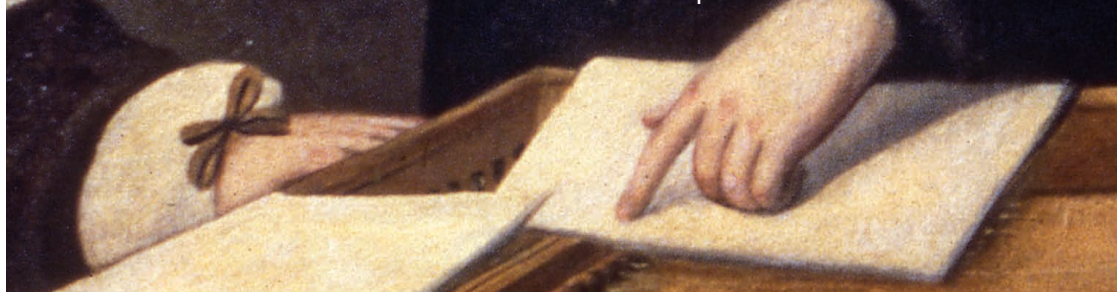

